\title{
Adherence to antiretroviral therapy among HIV/ AIDS patients in the context of early treatment initiation in Vietnam
}

This article was published in the following Dove Press journal:

Patient Preference and Adherence

Hue Thi Mai,' Giang Minh Le, ${ }^{1,2}$ Bach Xuan Tran, ${ }^{1,3,4} \mathrm{Ha}$ Ngoc Do, ${ }^{5}$ Carl A Latkin, ${ }^{3}$ Luong Thanh Nguyen, ${ }^{6}$ Thao Phuong Thi Thai, ${ }^{7,8}$ Huong Thi Le, ${ }^{9}$ Anh Toan Ngo, ${ }^{10}$ Cuong Tat Nguyen, "' Cyrus SH Ho, ${ }^{12}$ Roger $\mathrm{CM} \mathrm{Ho} \mathrm{H}^{13}$

'Institute for Preventive Medicine and Public Health, Hanoi Medical University, Hanoi,Vietnam; ${ }^{2}$ Center for Research and Training on HIVIAIDS (CREATA), Hanoi Medical University, Hanoi, Vietnam; ${ }^{3}$ Bloomberg School of Public Health, Johns Hopkins University, Baltimore, MD, USA; ${ }^{4}$ Vietnam Young Physician Association, Hanoi, Vietnam; ${ }^{5}$ Youth Research Institute, Vietnam (YRI)-Ho Chi Minh Communist Youth Union, Hanoi, Vietnam; ${ }^{6}$ Center of Excellence in Evidence-based Medicine, Nguyen Tat Thanh University, Ho Chi Minh City, Vietnam; ${ }^{7}$ Department of General Planning, Friendship Hospital, Hanoi, Vietnam; ${ }^{8}$ Department of Cardiology, Friendship Hospital, Hanoi, Vietnam; ${ }^{9} V$ ietnam Administration of HIVIAIDS Control, Hanoi, Vietnam; ${ }^{10} \mathrm{National}$ Hospital of Obstetrics and Gynecology, Hanoi, Vietnam; "Institute for Global Health Innovations, Duy Tan University, Da Nang, Vietnam; ${ }^{12}$ Department of Psychological Medicine, National University Hospital, Singapore, Singapore; ${ }^{13}$ Department of Psychological Medicine, Yong Loo Lin School of Medicine, National University of Singapore, Singapore, Singapore
Correspondence: Hue Thi Mai Institute for Preventive Medicine and Public Health, Hanoi Medical University, No. I Ton That Tung Street, Dong Da District, Hanoi 100000, Vietnam Email huemt93@gmail.com
Purpose: This study aimed to assess the antiretroviral therapy (ART) compliance among patients with HIV/AIDS and its associated factors in the context of universal ART initiation in Vietnam.

Patients and methods: A cross-sectional survey was conducted in five ART clinics located in three provinces, such as Hanoi, Thanh Hoa, and Lao Cai, from July to September 2017. Overall, adherence to ART in the last month was measured using a 100-point Visual Analog Scale (VAS). Besides, information about forgetting doses in the last 4 days and delaying taking pills in the last 7 days was also reported.

Results: Among 482 patients, the suboptimal adherence rate was 54.5\%. Noncurrent smoking (coefficient $=4.19,95 \%$ CI $0.42-7.97$ ), higher baseline CD4 count (coefficient $=4.35,95 \%$ CI $0.58-8.13$ ), and no traveling difficulties (coefficient $=6.17,95 \%$ CI 2.27-10.06) were predictors of higher VAS adherence score. Suboptimal adherence was associated with mountainous residence $(\mathrm{OR}=5.34,95 \% \mathrm{CI} 2.81-10.16)$. Female respondents were less likely to delay taking pills in the last 7 days (OR $=0.19,95 \%$ CI $0.07-0.52)$.

Conclusion: Our study embraced early ART initiation in Vietnam; however, this approach should be parallel with appropriate resource allocation and service delivery.

Keywords: HIV/AIDS, antiretroviral therapy, ART adherence, Visual Analog Scale, VAS

\section{Introduction}

HIV/AIDS has now evolved from an acute fatal disease to a chronic illness thanks to the extensive antiretroviral therapy (ART) access. ${ }^{1}$ This treatment reduces mortalities, morbidities, and opportunistic infections and prolongs survival. ${ }^{2,3}$ In addition, it helps to reduce HIV transmission in the community. ${ }^{4,5}$ Therefore, enhancing ART coverage is a principle strategy to end HIV/AIDS. Until June 2017, there were more than 20.9 million HIV/AIDS individuals enrolling in ART program. ${ }^{6}$ In 2015, the WHO promulgated a consolidated ART treatment guideline, promoting the universal ART access for all HIV-positive individuals regardless of CD4 cell count. ${ }^{7}$

Vietnam has adopted WHO's recommendations since 2017 with the decision number, 5418/QD-BYT, issued by the Ministry of Health. ${ }^{8}$ These efforts have shown the strong commitment to the "90-90-90 goals" toward ending the AIDS epidemic by $2030 .{ }^{9}$ However, this strategy is subjected to new challenges in the context of shrunken funds for HIV/AIDS control in Vietnam. Previously, approximately $95 \%$ of antiretroviral (ARV) drugs were funded by international organizations and only 5\% from the government budget. ${ }^{10}$ However, international funding resources have been speedily cut in recent years. Thus, early ART initiation may create greater financial 
burdens among HIV patients. Moreover, being enrolled in ART at healthy stage possibly leads to disease optimism. A previous study suggested that "feeling healthy" is a strong predictor of ART refusal. ${ }^{11}$ Although many studies in Vietnam have assessed the levels of ART adherence, ${ }^{12,13}$ the potential mechanisms of how early ART eligibility may predict the levels of ART adherence have not been well studied. Therefore, our study aimed to assess the levels of ART adherence and associated factors among HIV/AIDS patients in the context of universal ART in Vietnam.

\section{Patients and methods}

\section{Study settings}

A cross-sectional study was conducted from July to September 2017 in three provinces: Ha Noi, Thanh Hoa, and Lao Cai. Hanoi represented an area with a diversity of HIV risk behaviors including unsafe sex practice and drug injection. Thanh Hoa represented a setting with the high prevalence of drug trafficking. Lao Cai is the embodiment of the mountainous area with the complexity of HIV risk behaviors as well as illicit drug trafficking due to a large border with other countries. Five chosen ART clinics included the following: Thanh Hoa Provincial HIV/AIDS Control Center, Quang Xuong General Hospital, Ung Hoa General Hospital, Ba Vi General Hospital, Bao Thang General Hospital. The first clinic was the provincial level, and the remaining clinics were the district level.

\section{Study design and patient recruitment}

We selected patients based on the following criteria: 1) being at least 18 years old, 2) being present during the study period, 3) having ARV treatment at chosen clinics, 4) agreeing to involve in the study, 5) not having cognitive disabilities. All the eligible patients were clearly explained about the study purposes. If they agreed to participate in the study, they were asked to provide a written informed consent to confirm their participation. There were 482 patients participating in the study.

\section{Measures and instrument}

A structured questionnaire was used for 20-minute face-toface interviews. The collected information is given in the following sections.

\section{Sociodemographic characteristics}

Sociodemographic characteristics were as follows: age, location, marital status, education, employment, and travel difficulties.

\section{Clinical characteristics}

Data on Visual Analog Scale (VAS) adherence score, forgetting pills in the last 4 days, delaying taking pills in the last week were collected. We used 100-point VAS with 0 indicating "absolute non-adherence" and 100 indicating "excellent adherence" in the last 30 days. ${ }^{14}$ VAS score equaling to at least 95\% was defined as "optimal adherence"; otherwise, it was considered "suboptimal adherence." 15 Besides, the patients were asked whether they delayed taking pills in the last 7 days. Moreover, we asked patients to report HIV/ AIDS stages, ART duration, and ART treatment satisfaction. Data on initial/last CD4 count were extracted from patients' medical records.

\section{Risk behaviors}

We collected information regarding current smoking, alcohol dependence, history of drug use/drug injection, and current drug use. Alcohol Use Disorders Identification Test-Consumption (AUDIT-C) was utilized to screen alcohol dependence with score ranging from 0 to 12. Patients were characterized as hazard drinkers if the score was 4 or above in males and 3 or above in females. ${ }^{16}$ Current tobacco use was defined if patients smoked in the last 30 days.

\section{Statistical analyses}

Data were cleaned and analyzed by Stata (version 12; StataCorp LP, College Station, TX, USA). Missing data were handled using list-wise deletion strategy. ${ }^{17}$ To identify differences between men and women, we utilized Mann-Whitney $U$, chi-squared, and Fisher's exact tests. Multivariate Tobit and logistic regression models were used to detect potential predictors of VAS adherence score, suboptimal adherence, and delayed taking pills in the last week. A stepwise backward model with $P$-value of $<0.2$ was used to reduce the regression models. Results were considered statistically significant if $P$-value was $<0.05$.

\section{Ethical considerations}

The study protocol was reviewed and approved by the institutional review board of Hanoi Medical University. Patients' personal information was completely confidential, and they could stop interviewing at any time or reject to answer any questions. For CD4 cell count, we also requested permissions from patients before extracting data from medical records. 


\section{Results}

Table 1 summarizes the sociodemographic characteristics of respondents. The majority attained less than high school (66.0\%), lived in urban areas (70.6\%), and lived with spouse/ partners $(66.5 \%)$. Nearly $40 \%$ perceived barriers in traveling to ART clinics. The average age of males (39.3 years, $\mathrm{SD}=8.0$ ) was higher than that of females (36.8 years, $\mathrm{SD}=8.4 ; P<0.01)$.

Most of the respondents had an initial CD4 cell count of $\geq 350$ cells $/ \mathrm{mm}^{3}$ (53.0\%), in which male respondents had higher baseline CD4 cell count than female respondents $(P<0.01)$, which is summarized in Table 2. With regard to HIV stages, asymptomatic patients were dominant $(82.6 \%)$ and only $3.9 \%$ were in AIDS stage. The average ART duration was 3.8 ( $\mathrm{SD}=2.5$ ), and approximately 93\% were completely satisfied with ART treatment outcomes. The proportion of patients having methadone maintenance treatment (MMT) was $16.5 \%$, in which the percentage of patients co-treated with MMT was higher in females than that in males $(P<0.01)$.

The assessments of risk behaviors are summarized in Table 3. One-third of respondents were hazardous drinkers $(38.5 \%)$, and more than half of patients reported that they were current smokers. Besides, $44.8 \%$ used to addict to the illicit drug, and $14.1 \%$ currently used the drug. The history of drug injection was commonly reported among respondents $(41.2 \%)$. Rates of various health risk behaviors, such as hazard drinking, smoking, history of drug use/drug injection, and current drug use, were significantly higher among males in comparison with females $(P<0.01)$.
Table 4 summarizes that the mean percentage of adherence in the last month was $89.3(\mathrm{SD}=8.2)$. There were $45.5 \%$ patients achieving optimal adherence, $3.9 \%$ patient forgetting taking pills in the last 4 days, and $12.5 \%$ delaying taking pills in the last week.

Table 5 summarizes that noncurrent smoking (coefficient $=4.19,95 \%$ CI $0.42-7.97$ ), baseline CD4 count of at least 500 cells $/ \mathrm{mm}^{3}$ (coefficient $=4.35,95 \%$ CI $0.58-8.13$ ), and no traveling difficulties (coefficient $=6.17,95 \% \mathrm{CI}$ 2.27-10.06) were strong predictors of increased VAS score. Meanwhile, mountainous residence was associated with suboptimal adherence (OR $=5.34,95 \%$ CI 2.81-10.16). In addition, female respondents were less likely to delay taking pills in the last 7 days ( $\mathrm{OR}=0.19,95 \%$ CI $0.07-0.52$ ).

\section{Discussion}

The current study endorses the high prevalence of ART suboptimal adherence among HIV/AIDS patients in the context of early ART eligibility in Vietnam. Mountainous residence, travel difficulties, and current smoking were strong predictors of suboptimal adherence. In contrast, being females and having initial CD4 counts of at least $500 \mathrm{cell} / \mathrm{mm}^{3}$ were associated with optimal adherence.

The suboptimal adherence rate was considerably higher in comparison with previously published studies in Vietnam. ${ }^{12,13}$ This may be due to the data collection time as we conducted this study after the implementation of early ART initiation program. Literature has highlighted that HIV individuals might be less motivated to comply with ART regimens when they are clinically asymptomatic. ${ }^{11,18}$

Table I Sociodemographic characteristics of respondents

\begin{tabular}{|c|c|c|c|c|c|c|c|}
\hline \multirow[t]{2}{*}{ Characteristics } & \multicolumn{2}{|l|}{ Male } & \multicolumn{2}{|c|}{ Female } & \multicolumn{2}{|l|}{ Total } & \multirow[t]{2}{*}{$P$-value } \\
\hline & $\mathbf{n}$ & $\%$ & $\mathbf{n}$ & $\%$ & $\mathbf{n}$ & $\%$ & \\
\hline \multicolumn{7}{|l|}{ Education } & 0.60 \\
\hline Less than high school & 194 & 65.5 & $|2|$ & 66.9 & 315 & 66.0 & \\
\hline High school & 89 & 30.1 & 49 & 27.1 & 138 & 28.9 & \\
\hline More than high school & 13 & 4.4 & II & 6.1 & 24 & 5.3 & \\
\hline \multicolumn{7}{|l|}{ Geographic location } & 0.6 \\
\hline Rural & 92 & 31.0 & 49 & 26.8 & $14 \mid$ & 29.4 & \\
\hline Urban & 84 & 28.3 & 58 & 31.7 & 142 & 29.6 & \\
\hline Mountainous & 121 & 40.7 & 76 & 41.5 & 197 & 41.0 & \\
\hline \multicolumn{7}{|l|}{ Marital status } & $<0.01$ \\
\hline Single & 59 & 19.9 & 16 & 8.8 & 75 & 15.7 & \\
\hline Living with spouse/partner & 218 & 73.7 & 100 & 55.0 & 318 & 66.5 & \\
\hline Divorced/separated/widowed & 19 & 6.4 & 66 & 36.3 & 85 & 17.8 & \\
\hline \multicolumn{7}{|c|}{ Difficulty in traveling to the clinic } & 0.08 \\
\hline Yes & 106 & 36.1 & 80 & 44.2 & 186 & 39.2 & \\
\hline \multirow[t]{2}{*}{ No } & 188 & 64.0 & 101 & 55.8 & 289 & 60.8 & \\
\hline & Mean & SD & Mean & SD & Mean & SD & \\
\hline Age (years) & 39.3 & 8.0 & 36.8 & 8.4 & 38.4 & 8.3 & $<\mathbf{0 . 0 1}$ \\
\hline
\end{tabular}


Table 2 Clinical characteristics of respondents

\begin{tabular}{|c|c|c|c|c|c|c|c|}
\hline \multirow[t]{2}{*}{ Characteristics } & \multicolumn{2}{|l|}{ Male } & \multicolumn{2}{|c|}{ Female } & \multicolumn{2}{|l|}{ Total } & \multirow[t]{2}{*}{$P$-value } \\
\hline & $\mathrm{n}$ & $\%$ & $\mathbf{n}$ & $\%$ & $\mathbf{n}$ & $\%$ & \\
\hline \multicolumn{7}{|c|}{ Initial CD4 count (cells/mm $\left./ \mathrm{mm}^{3}\right)$} & $<0.01$ \\
\hline$<200$ & 77 & 33.1 & 21 & 16.3 & 98 & 27.1 & \\
\hline $200-350$ & 51 & 21.9 & 21 & 16.3 & 72 & 19.9 & \\
\hline$\geq 350$ & 105 & 45.1 & 87 & 67.4 & 192 & 53.0 & \\
\hline \multicolumn{7}{|c|}{ Last CD4 count (cells/mm ${ }^{3}$ ) } & $<0.01$ \\
\hline$<200$ & 45 & 19.3 & 13 & 10.1 & 58 & 16.0 & \\
\hline $200-350$ & 55 & 23.6 & 15 & 11.6 & 70 & 19.3 & \\
\hline$\geq 350$ & 133 & 57.1 & 101 & 78.3 & 234 & 64.6 & \\
\hline \multicolumn{7}{|l|}{ HIV stage } & 0.30 \\
\hline Asymptomatic & 156 & 74.6 & 105 & 79.6 & 261 & 76.5 & \\
\hline Symptomatic & 53 & 25.4 & 27 & 20.5 & 80 & 23.5 & \\
\hline \multicolumn{7}{|c|}{ Co-treatment with MMT } & $<0.0$ I \\
\hline Yes & 71 & 24.7 & 3 & 1.9 & 74 & 16.5 & \\
\hline No & 217 & 75.4 & 158 & 98.1 & 375 & 83.5 & \\
\hline \multicolumn{7}{|c|}{ Treatment satisfaction } & 0.20 \\
\hline Totally satisfied & 257 & 91.1 & 170 & 95.0 & 427 & 92.6 & \\
\hline Partially satisfied & 24 & 8.5 & 8 & 4.5 & 32 & 6.9 & \\
\hline \multirow[t]{2}{*}{ Not satisfied } & I & 0.4 & I & 0.6 & 2 & 0.4 & \\
\hline & Mean & SD & Mean & SD & Mean & SD & \\
\hline ART duration & 3.6 & 2.4 & 4.2 & 2.7 & 3.8 & 2.5 & 0.06 \\
\hline
\end{tabular}

This hypothesis requires further studies to elaborate the potential mechanisms of how physical health status could predict ART compliance. Another potential justification was that early ART initiation could increase treatment costs for CD4/viral load tests and travels. A prior study in Vietnam indicated that the amount of willingness to pay for $\mathrm{CD} 4 /$ viral load testing was only a fraction of the current cost. ${ }^{19}$ This highlights the importance of financial mobilization to ensure

Table 3 Health-related risk behaviors of respondents

\begin{tabular}{|c|c|c|c|c|c|c|c|}
\hline \multirow[t]{2}{*}{ Characteristics } & \multicolumn{2}{|c|}{ Male } & \multicolumn{2}{|c|}{ Female } & \multicolumn{2}{|c|}{ Total } & \multirow[t]{2}{*}{$P$-value } \\
\hline & $\mathbf{n}$ & $\%$ & $\mathbf{n}$ & $\%$ & $\mathbf{n}$ & $\%$ & \\
\hline \multicolumn{7}{|l|}{ Hazard drinking } & $<0.01$ \\
\hline Yes & 172 & 57.9 & 12 & 6.6 & 184 & 38.5 & \\
\hline No & 125 & 42.1 & 169 & 93.4 & 294 & 61.5 & \\
\hline \multicolumn{7}{|l|}{ Current smoking } & $<0.01$ \\
\hline Yes & 218 & 75.17 & 7 & 3.85 & 225 & 47.67 & \\
\hline No & 72 & 24.83 & 175 & 96.15 & 247 & 52.33 & \\
\hline \multicolumn{7}{|c|}{ History of drug use } & $<0.01$ \\
\hline Yes & 208 & 70.0 & 7 & 3.8 & 215 & 44.8 & \\
\hline No & 89 & 30.0 & 176 & 96.2 & 265 & 55.2 & \\
\hline \multicolumn{7}{|l|}{ Current drug use } & 0.68 \\
\hline Yes & 140 & 68.6 & 4 & 57.1 & 144 & 68.3 & \\
\hline No & 64 & 31.4 & 3 & 42.9 & 67 & 31.8 & \\
\hline \multicolumn{7}{|c|}{ History of drug injection } & $<0.01$ \\
\hline Yes & 191 & 64.8 & 6 & 3.3 & 197 & 41.2 & \\
\hline No & 104 & 35.3 & 177 & 96.7 & 281 & 58.8 & \\
\hline
\end{tabular}

Table 4 Self-reported adherence to ART

\begin{tabular}{|c|c|c|c|c|c|c|c|}
\hline \multirow[t]{2}{*}{ Characteristics } & \multicolumn{2}{|l|}{ Male } & \multicolumn{2}{|c|}{ Female } & \multicolumn{2}{|l|}{ Total } & \multirow[t]{2}{*}{$P$-value } \\
\hline & $\mathbf{n}$ & $\%$ & $\mathbf{n}$ & $\%$ & $\mathbf{n}$ & $\%$ & \\
\hline \multicolumn{7}{|c|}{ Optimal adherence } & $<0.05$ \\
\hline Yes & 117 & 41.6 & 89 & 51.7 & 206 & 45.5 & \\
\hline No & 164 & 58.4 & 83 & 48.3 & 247 & 54.5 & \\
\hline \multicolumn{7}{|c|}{ Forgot doses in the last 4 days } & 0.34 \\
\hline Yes & 13 & 4.5 & 5 & 2.8 & 18 & 3.9 & \\
\hline No & 274 & 95.5 & 175 & 97.2 & 449 & 96.2 & \\
\hline \multicolumn{7}{|c|}{ Delayed taking pills in the last week } & $<0.01$ \\
\hline Yes & 49 & 17.3 & 9 & 5.0 & 58 & 12.5 & \\
\hline \multirow[t]{2}{*}{ No } & 234 & 82.7 & 171 & 95.0 & 405 & 87.5 & \\
\hline & Mean & SD & Mean & SD & Mean & SD & \\
\hline $\begin{array}{l}\text { VAS adherence } \\
\text { score }\end{array}$ & 88.8 & 12.8 & 90.2 & 15.6 & 89.3 & 8.2 & $<0.01$ \\
\hline
\end{tabular}

Abbreviations: ART, antiretroviral therapy; VAS, Visual Analog Scale.

the quality, adherence, and treatment outcomes, especially in the context of universal ART program in Vietnam.

The regression model showed that female patients were more likely to comply with treatment regimens. The result was in line with various studies in China, ${ }^{20}$ sub-Saharan Africa, and Asia, ${ }^{21}$ while contradictory results were affirmed in several studies in the USA, ${ }^{22}$ British Columbia, and Canada. ${ }^{23}$ The heterogeneity across studies, perhaps, could be explained by the sociocultural differences. In many Asian countries, husband-wife HIV transmission was highly prevalent due to the acceptance of husband's extramarital sex, delayed notification of husbands' HIV/AIDS status, and unawareness of husband's promiscuity. ${ }^{24}$ Thus, we supposed that the passive HIV/AIDS infection motivated women to comply with ART regimens - the lifesaving. Besides, men have greater risks of diverse HIV risk behaviors such as multiple types of drug abuse, ${ }^{25}$ alcohol use, ${ }^{26}$ and tobacco use, ${ }^{27}$ which were significant predictors of suboptimal adherence. . $22,23,28,29$

Of note, mountainous residents were less likely to achieve optimal adherence. This issue may be due to socioeconomic disadvantages. A study by Tran et al in Vietnam revealed that ethnic minorities had lower access, adherence, and outcome of ART services due to socioeconomic inequity. ${ }^{30}$ Besides, we observed a positive correlation between poor adherence and travel difficulty. We highly recommend the integration of ART in commune health centers to elevate the service accessibility. In fact, Vietnam successfully piloted the treatment 2.0 initiatives in 2011 regarding the joint initiative of WHO and the Joint United Nation Program on HIV/AIDS (UNAIDS). Five main elements included decentralizing and integrating HIV services into commune health centers; HIV testing, care, 
Table 5 Factors associated with ART suboptimal adherence

\begin{tabular}{|c|c|c|c|c|c|c|}
\hline \multirow[t]{2}{*}{ Characteristics } & \multicolumn{2}{|l|}{ VAS score } & \multicolumn{2}{|c|}{ Suboptimal adherence } & \multicolumn{2}{|c|}{$\begin{array}{l}\text { Delayed taking pills in } \\
\text { the last week }\end{array}$} \\
\hline & Coefficient & $95 \% \mathrm{Cl}$ & OR & $95 \% \mathrm{Cl}$ & OR & $95 \% \mathrm{Cl}$ \\
\hline \multicolumn{7}{|l|}{ Sex (vs male) } \\
\hline Female & & & $0.63 *$ & $(0.36-1.09)$ & $0.19 * *$ & $(0.07-0.52)$ \\
\hline \multicolumn{7}{|c|}{ Location (vs urban) } \\
\hline Mountainous & $-4.87 * * *$ & $(-9.00$ to -0.74$)$ & $5.34 * *$ & $(2.8 I-10.16)$ & $0.44^{* * *}$ & $(0.19-1.00)$ \\
\hline \multicolumn{7}{|c|}{ Employment (vs unemployed) } \\
\hline Employed & $-5.29 * * *$ & $(-9.62$ to -0.96$)$ & $1.95 * * *$ & $(1.06-3.60)$ & & \\
\hline \multicolumn{7}{|c|}{ Education (vs < high school) } \\
\hline High school & -2.84 & $(-6.79$ to 1.12$)$ & & & & \\
\hline$>$ High school & $8.02 *$ & $(-1.25$ to 17.30$)$ & & & & \\
\hline \multicolumn{7}{|c|}{ Travel obstacles (vs yes) } \\
\hline No & $6.17^{* *}$ & $(2.27-10.06)$ & 0.70 & $(0.4 I-1.19)$ & $0.28 * *$ & $0.14-0.58$ \\
\hline \multicolumn{7}{|c|}{ Current smoking (vs yes) } \\
\hline No & $4.19 * * *$ & $(0.42-7.97)$ & & & & \\
\hline \multicolumn{7}{|c|}{ Initial CD4 count (vs $<500$ cell//mm ${ }^{3}$ ) } \\
\hline$\geq 500 \mathrm{cell} / \mathrm{mm}^{3}$ & $4.35^{* * *}$ & $(0.58-8.13)$ & $0.35 * *$ & $(0.17-0.72)$ & & \\
\hline \multicolumn{7}{|c|}{ Last CD4 count (vs $<500$ cell//mm ${ }^{3}$ ) } \\
\hline$\geq 500 \mathrm{cell} / \mathrm{mm}^{3}$ & & & $2.02 *$ & $(0.93-4.43)$ & & \\
\hline
\end{tabular}

Notes: $* P<0.1 ; * * P<0.01 ; * * * P<0.05$.

Abbreviations: ART, antiretroviral therapy; VAS, Visual Analog Scale.

and treatment at the commune level; early diagnosis with quick tests; optimizing treatment regimens; and mobilizing community participation. Our findings embraced the expansion of this model in hard-to-reach locations.

It was noteworthy that those with high initial CD4 cell counts $\left(>500 \mathrm{cell} / \mathrm{mm}^{3}\right)$ were more likely to achieve optimal adherence. We assumed that those with clinical symptoms might receive multiple drug regimens, leading to a higher likelihood of ART non-adherence due to pill burdens and drug interactions. ${ }^{31}$ Some previous studies suggested that higher pre-ART CD4 cell count was associated with decreased mortality, improved treatment outcomes, and increased adherence ${ }^{32-34}$ Our findings supported the national guideline on HIV/AIDS care which increased the threshold of CD4 cell counts for ART initiation from $<350$ cell $/ \mathrm{mm}^{3}$ in 2011 to $<500 \mathrm{cell} / \mathrm{mm}^{3}$ in 2015 , and most recently, enrolled all HIV-diagnosed patients in ART regardless of CD4 counts.

Our study affirmed smoking as a strong predictor of suboptimal adherence. It has been well evident that HIV-infected smokers are at greater risks of low CD4 counts, pulmonary infections, and lung cancer; ${ }^{35}$ and nicotine dependence could alleviate health benefits of ART adherence. ${ }^{36}$ While HIVinfected individuals are at greater risks of smoking than the general population, ${ }^{37}$ tobacco cessation has been not properly paid attention in the HIV-infected group. Thus, it is called for pragmatic smoking cessation programs to minimize the disease burdens and promote the treatment outcomes among HIV-infected patients.

The core implication of our study is that early ART initiation should be parallel with appropriate resource allocation and service delivery. This, perhaps, could be performed by mobilizing the government budget, including health insurance, and decentralizing/integrating HIV services into commune health centers. Besides, tobacco cessation programs should be implemented in ART clinics with dynamic forms such as behavioral therapies and nicotine replacement therapies.

Our study has several strengths. First, this current study provided up-to-date evidence on the level of ART adherence and associated factors in the context of early treatment in Vietnam. Thus, this current study would contribute to the benefits of early ART initiation. Second, as we recruited patients from urban, rural, and mountainous locations, it allowed us to obtain the sample size with diverse sociodemographic backgrounds, increasing the generalizability of the study population. Apart from these advantages, this study was subjected to several limitations. Although the selfreported measure was the most convenient method to evaluate ART adherence, ${ }^{38}$ it might be subjected to recall and social desirability biases. Other direct methods such as therapeutic drug monitoring and biomarkers may promise more accurate results. Yet, costs and resources related to such methods should be taken into account. Besides, missing data might occur because patients could refuse to answer any questions 
or provide any information. To minimize missing data, interviewers explained clearly about the study purposes and emphasized the assurance of information confidentiality.

\section{Conclusion}

Our study endorsed the high prevalence of ART suboptimal adherence among HIV-infected patients. Optimal adherence was associated with female patients or patients who had high baseline CD4 count, while suboptimal adherence was linked with mountainous residence and current smoking. While we embrace early ART eligibility in Vietnam, it should be parallel with improved resource allocation and service delivery.

\section{Author contributions}

HTM, BXT, GML, HTL, and HND conceived the study. BXT, CTN, GML, HTL, and HND designed the study. HTM, CTN, LTN, TPTT, and ATN implemented the study and collected the data. HTM, CTN, TPTT, LTN, and ATN analyzed the data. HTM, BXT, and GML drafted the first manuscript. All authors contributed toward data analysis, drafting and critically revising the paper and agree to be accountable for all aspects of the work.

\section{Disclosure}

The authors report no conflicts of interest in this work.

\section{References}

1. Ayalew J, Moges H, Sahu O, Worku A. Identifying Factors Related to the Survival of AIDS Patients under the Follow-up of Antiretroviral Therapy (ART): The Case of South Wollo. International Journal of Data Envelopment Analysis and *Operations Research*. 2014;1(2):21-27.

2. Smith K, Powers KA, Kashuba AD, Cohen MS. HIV-1 treatment as prevention: the good, the bad, and the challenges. Curr Opin HIV AIDS. 2011;6(4):1-325.

3. Odafe S, Idoko O, Badru T, et al. Patients' demographic and clinical characteristics and level of care associated with lost to follow-up and mortality in adult patients on first-line ART in Nigerian hospitals. $J$ Int AIDS Soc. 2012;15(2):1742409/18 09/27/received 06/25/revised 08/20/ accepted.

4. Tanser F, Bärnighausen T, Grapsa E, Zaidi J, Newell ML. High coverage of ART associated with decline in risk of HIV acquisition in rural KwaZulu-Natal, South Africa. Science. 2013;339(6122):966-971.

5. Mcclelland RS, Richardson BA, Cherutich P, et al. A 15-year study of the impact of community antiretroviral therapy coverage on HIV incidence in Kenyan female sex workers. AIDS. 2015;29(17):2279-2286.

6. USAIDS. Fact Sheet - Latest Statistics on the Status of the AIDS Epidemic; 2017. Available from: www.unaids.org/sites/default/files/ media_asset/UNAIDS_FactSheet_en.pdf. Accessed September 3, 2018.

7. World Health Organization. Guideline on When to Start Antiretroviral Therapy and on Pre-Exposure Prophylaxis for HIV; 2015. Available from: http://www.who.int/hiv/pub/guidelines/earlyrelease-arv/en/. Accessed September 3, 2018.

8. The Ministry of Health of Viet Nam. Decision on Guidelines for HIV/ AIDS Care; 2017.
9. UNAIDS. Fast Track Strategy; 2014. Available from: www.unaids. org/en/resources/campaigns/World-AIDS-Day-Report-2014. Accessed September 3, 2018.

10. Health Finance \& Governance. Mobilizing Domestic Funding, Resources to Fight HIV and AIDS; 2014. Available from: https://www. hfgproject.org/mobilizing-domestic-resources-hiv-aids/. Accessed September 3, 2018.

11. Katz IT, Essien T, Marinda ET, et al. Antiretroviral therapy refusal among newly diagnosed HIV-infected adults. AIDS. 2011;25(17): 2177-2181.

12. Tran BX, Nguyen LT, Nguyen NH, Hoang QV, Hwang J. Determinants of antiretroviral treatment adherence among HIV/AIDS patients: a multisite study. Glob Health Action. 2013;6:19570.

13. do HM, Dunne MP, Kato M, Pham CV, Nguyen KV. Factors associated with suboptimal adherence to antiretroviral therapy in Viet Nam: a cross-sectional study using audio computer-assisted self-interview (ACASI). BMC Infect Dis. 2013;13:154-15403/27 07/13/received 03/21/accepted.

14. Giordano TP, Guzman D, Clark R, Charlebois ED, Bangsberg DR. Measuring adherence to antiretroviral therapy in a diverse population using a visual analogue scale. HIV Clin Trials. 2004;5(2):74-79.

15. Kobin AB, Sheth NU. Levels of adherence required for virologic suppression among newer antiretroviral medications. Ann Pharmacother. 2011;45(3):372-379.

16. Bush K, Kivlahan DR, Mcdonell MB, Fihn SD, Bradley KA. The AUDIT alcohol consumption questions (AUDIT-C): an effective brief screening test for problem drinking. Ambulatory Care Quality Improvement Project (ACQUIP). Alcohol Use Disorders Identification Test. Arch Intern Med. 1998;158(16):1789-1795.

17. Kang H. The prevention and handling of the missing data. Korean $J$ Anesthesiol. 2013;64(5):402-406.

18. Nachega JB, Uthman OA, del Rio C, Mugavero MJ, Rees H, Mills EJ. Addressing the Achilles' heel in the HIV care continuum for the success of a test-and-treat strategy to achieve an AIDS-free generation. Clin Infect Dis. 2014;59 Supp1 1:S21-S27.

19. Nguyen QLT, Nguyen LH, Tran BX, et al. Co-financing for viral load monitoring during the course of antiretroviral therapy among patients with HIV/AIDS in Vietnam: A contingent valuation survey. PLoS One. 2017;12(2):e0172050.

20. Wang W, Liu W, Chen T, et al. Factors influencing antiretroviral therapy adherence among HIV-infected people on antiretroviral therapy in Ili Kazakh Autonomous Prefecture. Zhonghua Yu Fang Yi Xue Za Zhi. 2017;51(2):160-164.

21. Bijker R, Jiamsakul A, Kityo C, et al. Adherence to antiretroviral therapy for HIV in sub-Saharan Africa and Asia: a comparative analysis of two regional cohorts. J Int AIDS Soc. 2017;20(1):21218.

22. Beer L, Skarbinski J. Adherence to antiretroviral therapy among HIVinfected adults in the United States. AIDS Educ Prev. 2014;26(6): 521-537.

23. O'Neil CR, Palmer AK, Coulter S, et al. Factors associated with antiretroviral medication adherence among HIV-positive adults accessing highly active antiretroviral therapy (HAART) in British Columbia, Canada. J Int Assoc Physicians AIDS Care. 2012;11(2):134-141.

24. Yang Y, Lewis FM, Wojnar D. Culturally Embedded Risk Factors for Cambodian Husband-Wife HIV Transmission: From Women's Point of View. J Nurs Scholarsh. 2016;48(2):154-162.

25. Substance Abuse and Mental Health Services Administration. Results from the 2013 National Survey on Drug Use and Health: Summary of National Findings, NSDUH Series H-48, HHS Publication No. (SMA) 14-4863. Rockville, MD: Substance Abuse and Mental Health Services Administration, 2014.

26. Emslie C, Hunt K, Macintyre S. How similar are the smoking and drinking habits of men and women in non-manual jobs? Eur J Public Health. 2002;12(1):22-28. 
27. Tsai YW, Tsai TI, Yang CL, Kuo KN. Gender differences in smoking behaviors in an Asian population. J Womens Health. 2008;17(6): 971-978.

28. Sharma S, Khadga P, Dhungana GP, Chitrakar U. Medication adherence to antiretroviral therapy among patients visiting antiretroviral therapy center at Tribhuvan University Teaching Hospital, Kathmandu Nepal. Kathmandu University medical journal. Jan. 2013;11(41):50-53.

29. de Fatima Bonolo P, Ceccato M, Rocha GM, de Assis Acúrcio F, Campos LN, Guimarães MD. Gender differences in non-adherence among Brazilian patients initiating antiretroviral therapy. Clinics. 2013; 68(5):612-620.

30. Tran BX, Hwang J, Nguyen LH, et al. Impact of Socioeconomic Inequality on Access, Adherence, and Outcomes of Antiretroviral Treatment Services for People Living with HIV/AIDS in Vietnam. PLoS One 2016;11(12):e0168687.

31. Cantudo-Cuenca MR, Jiménez-Galán R, Almeida-Gonzalez CV, Morillo-Verdugo R. Concurrent use of comedications reduces adherence to antiretroviral therapy among HIV-infected patients. J Manag Care Spec Pharm. 2014;20(8):844-850.

32. Clouse K, Pettifor A, Maskew M, et al. Initiating antiretroviral therapy when presenting with higher CD4 cell counts results in reduced loss to follow-up in a resource-limited setting. AIDS. 2013;27(4):645-650.
33. Kitahata MM, Gange SJ, Abraham AG, et al. Effect of early versus deferred antiretroviral therapy for HIV on survival. N Engl J Med. 2009; 360(18):1815-1826.

34. Conen A, Wang Q, Glass TR, et al. Association of alcohol consumption and HIV surrogate markers in participants of the Swiss HIV cohort study. J Acquir Immune Defic Syndr. 2013;64(5):472-478.

35. Kumar SR, Swaminathan S, Flanigan T, Mayer KH, Niaura R. HIV \& smoking in India. The Indian Journal of Medical Research. 2009;130(1):15-22.

36. King RM, Vidrine DJ, Danysh HE, et al. Factors associated with nonadherence to antiretroviral therapy in HIV-positive smokers. AIDS Patient Care STDS. 2012;26(8):479-485.

37. Arday DR, Erdin BR, Giovino GA, Nelson DE, Smoking NDE. Smoking, HIV infection, and gay men in the United States. Tob Control. 1993; 2(2):156-158

38. Hawkshead J, Krousel-Wood MA. Techniques for Measuring Medication Adherence in Hypertensive Patients in Outpatient Settings. Disease Management \& Health Outcomes. 2007;15(2):109-118.
Patient Preference and Adherence

\section{Publish your work in this journal}

Patient Preference and Adherence is an international, peer-reviewed, open access journal that focuses on the growing importance of patient preference and adherence throughout the therapeutic continuum. Patient satisfaction, acceptability, quality of life, compliance, persistence and their role in developing new therapeutic modalities and compounds to optimize

\section{Dovepress}

clinical outcomes for existing disease states are major areas of interest for the journal. This journal has been accepted for indexing on PubMed Central. The manuscript management system is completely online and includes a very quick and fair peer-review system, which is all easy to use. Visit http://www. dovepress.com/testimonials.php to read real quotes from published authors. 